Ambient Science, 2016: Vol. 03(Sp1); 54-58

DOI:10.21276/ambi.2016.03.sp1.ra08

ambient

SCIENCE

Vol. 3(Sp1):54-58

Year 2016

\title{
Women's Psychological Sexual Disorder and Hypertensive Husbands
}

\section{Leili Mosalanezhad', Mahdi Asadi², Mohammad Zarenezhad ${ }^{3}$, Farzaneh Alipour ${ }^{4 *}$}

'Deducation Development Center, Jahrom,Fars, Iran

${ }^{2}$ Department of Emergency Medicine, Jahrom University of Medical Sciences,Fars, Iran

${ }^{3}$ Gastroenterohepatholology Research Center, Shiraz University of Medical Science, Shiraz, Iran

${ }^{3}$ Iranian Legal Medicine Research Center, Legal Medicine Organization, Tehran, Iran

${ }^{4}$ Student Research Committee, Jahom University of Medical Sciences, Jahrom, Fars, Iran

Study Area: Fars, Iran

Coordinate: $29^{\circ} 37^{\prime} \mathrm{N} ; 52^{\circ} 32^{\prime} \mathrm{E}$

Key words: Couple burnout, Sexual beliefs, Sexual assertiveness

\section{Introduction:}

Sexual behaviour is considered as one of the essential parameters in public health issues, especially for mental health (Esmaili et al., 2014). Sexual health is defined as integration coordination between mind, emotion and body, which leads to improvement in a relationship and considering love which is one of the most important parts in human relations (Bernhard, 2002). Hence, any biological disorder leads to an imbalance in the lifecycle, and lack of sexual satisfaction can be associated with sexual dysfunction. As the Sexual dysfunction is associated with anatomical or medical and psychological parameters, thus a little imbalance in it may cause severe discomfort in such a way that quality of life and interpersonal relationships would be highly affected (Bernhard, 2002). Chronic diseases could disturb sexual aspect of couples and hypertension as one of the commonest chronic disorders which affect sexual dysfunction and could alter the quality of life among the couples. Erectile dysfunction is one of the essential barriers in the treatment of hypertensive men. It has been shown that various antihypertensive drugs have a negative influence on sexual activity such as diuretics and b-

\section{Abstract}

Healthy sex is the basic need for the human being and constant interruption in it due to some chronic illness might end up the martial relationship. This study was aimed to compare the relationship between couple burnout, sexual assertiveness, and sexual dysfunctional beliefs in women with hypertensive and non-hypertensive husbands. The survey was conducted in the internal clinic, Jahrom university of medical sciences. Total 200 participants have included out of which 100 women were with hypertensive husbands and the others were with non-hypertensive husbands. Data were collected through demographic characteristics' questionnaire; couple burnout Measure, Hulbert index of sexual assertiveness and sexual dysfunctional beliefs Questionnaire. The proper statistical analysis was applied to evaluate the differences between 2 groups. Results concluded to one of the most important factors which contort and increases couple burnout are the wrong sexual beliefs regarding sexual function and sexual decisive in women regarding their husbands' sexual dysfunction.

blockers (Chiesa et al., 2003). Psychological sexual disorders of the couples suffering from chronic disease include couple burnout, lack of sexual assertiveness, and sexual dysfunctional beliefs (Khodabakhshi et al., 2014). Couple burnout could be described as exhaustion in the physical, emotional, and mental state as well as a factor responsible for depersonalization (Stackert \& Bursik, 2003). Sexual assertiveness refers to one's capability to make sexual relationships in order to be satisfied and initiating sexual behaviour with a partner or spouse. A Proper understanding of couple's each other desires and proper famine and masculine behaviours are required parameters in sexual assertiveness (Bai, 2009). In many societies, women face difficulty expressing their sexual needs or keep their individual dependency in marital relationships. The other components of sexual health are Sexual belief which could be explained as one's thoughts and ideas about sexual behaviours (Roberts, 2009; Nobre \& Pinto-Gouveia, 2003). Earlier studies have assessed sexual disorders in couples suffering from chronic diseases. Khodabakhshi et al. (2014) pointed out the psychological sexual problems in women with diabetic husbands and they compared sexual assertiveness, couple

*Corresponding Author: zarenezhad@hotmail.com 
burnout and sexual believes in 2 groups; diabetic and non-diabetic husbands (Koolaee et al., 2014). In an another study, a relationship between ischemic heart disease and sexual satisfaction was evaluated and effect of cardiac medication and cardiac disease on sexual satisfaction were assessed (Stackert \& Bursik, 2003). Sexual activity in hypertensive men was also compared with different treatment of hypertension and their proper effect was evaluated on sexual life (Bai, 2009) .

Based on psychological research on mental health and considering sexual disorder as one of the threatening cause for a martial relationship and the fact that statistics of this disorder due to cultural issues in Iran (country) has not been reported well, whereas focusing on studies associated with sexual health is highly recommended.

Though a large number of studies have concluded sexual dysfunction in hypertensive men, but yet no proper study has been performed to assess couple burnout, sexual assertiveness and sexual dysfunctional believes in women with hypertensive husbands and nonhypertensive husbands. Importance of cultural or contextual in non-presentation of these disorders by women also should be explored. Therefore this study aimed to assess male hypertension and its effects on female psychological disorders.

\section{Methodology:}

The research was done in internal clinics in Jahrom during in 2014-2015 Jahrom, Fars, Iran. Total 200 participants were divided into two groups: the first group included 100 women with hypertensive husbands and the second group included women with 100 women with nonhypertensive husbands.

Sampling : Purposive sampling method was used in this research.

Inclusion criteria: Women with hypertensive husbands take ACE and who have secondary causes of HTN.

Exclusion criteria: women those who have marriage duration less than 10 years or more than 20 years and having a husband with other physical and mental disorders and those who were taking other medication for diabetes mellitus or cardiac diseases and other significant diseases.

Further 100 married women with hypertensive husbands and 100 with non-hypertensive husbands were randomly selected by researchers were selected categorized with respect to the age group, socio-economic status, level of education. All the questionnaires were filled out by interviewers and women answered them independently. Before the implementing, the research the interviewers were trained in an orientation session where they were trained regarding the gathering of data and how to be handled sensitive ethical issues.

Research tools: data gathering were from 3 questionnaires which were done in 4 parts . 1st part was based on a demographic questionnaire which was prepared by the researchers to assess personal characteristics of the participants. This questionnaire included age, joband education.

Next questionnaire included Halbert indicator of sexual assertiveness (HISA).This questionnaire was to measure women's sexual assertiveness while interaction with others (Navid, 2006). This questionnaire included total 25 questions and each with 5 choices, acted as measuring scale. The choices ranked from "always" to "never"; "always $=4$, often $=3$, sometimes $=2$, rarely $=1$, and never $=0$ ". This questionnaire was normalised as per Iranian society. The alpha index was yielded 0.79 for the whole test. In Iran, Sanaee (2005) reported the content validity Index to be 0.91 .

Sexual dysfunctional beliefs questionnaire (SDBQ): this questionnaire was presented by Nobreh \& Pinto-Guya (2003) in which 40-questions are included to evaluate sexual beliefs and imaginations that are considered as the preparing factors causing sexual dysfunction in men and women in clinical literature. The questionnaire has been offered in two formats for men and women, which measures beliefs related to each gender specifically. Individuals were asked to disclose their opinion in a fivepoint Likert scale, which were ranked as- completely disagree $=1$, disagree $=2$, neither agree nor disagree $=3$, agree $=4$ and strongly agree $=5$. The subscales of women form were included 6 believes i.e., believes about woman's $\mathrm{X}$, sexuality as a sin, body image, priority of emotion upon sexuality and priority of motherhood duties upon the sexual relationship.

The reliability of test- retest for men and women versions with a four weeks interval, had an acceptable correlation $(\mathrm{r}=0.73, \mathrm{r}=\mathrm{0} .80)$. Chronbach's alpha value for men and women versions was reported to be 0.93 and 0.81 , respectively which approved the questionnaire's internal consistency. In the Persian version of this questionnaire internal consistency was calculated for men and women were 0.89 and 0.80 , respectively. The reliability of its convergence with the questionnaire of insufficient attitudes was also 0.76 . Also, the content validity of consistency reported by creators of SDBQ was 0.76 (Nobre \& Pinto-Gouveia, 2003).

Couple burnout measure (CBM): This questionnaire is a self-measure tool designed for measuring couple burnout. This questionnaire includes 21 items which are based on the reasons of burnout symptoms and has three principles.

Parts: physical (Collapse e.g. feeling tired, weakness and sleep disorders), emotional collapse (e.g. feeling depressed, despair, feeling trapped) and mental collapse (e.g. feeling worthless, frustration and showing anger to spouse). 
All these items were responded on a 7 point scale which are as follows: "Always $=7$, often $=6$, usually $=5$, sometimes $=4$, rarely $=3$, once $=2$, and never $=1$ " $(24)$. In Iran, Navid measured Chronbach's alpha value for this questionnaire that was o.86. In Adibrad and Adibrad study, the p-value of test- retest for one month, two months and four months period was $0.89,0.76$ and 0.66 , respectively. The internal consistency for most respondents was measured by the alpha index which ranged from 0.91-0.93 and content validity was claimed o.82 All the questionnaires were filled by participants. All the questionnaires are normalised in Iranian society (Khodabakhshi et al., 2014).

Ethical Committee Approval: the proposal extracted from this paper was confirmed by Ethics Committee of Jahrom University of medical sciences. Patient consensus form was collected and a calm place was determined for the women to fill out the questionnaire.

Statistical analysis: data analysis was done using descriptive statistics, frequency, percentage, mean, variance and standard deviation. Also, analytic statistical methods were used such as mean and SD, ANOVA and LSD tests. The conf idence level was identif ied $\mathrm{p}<0.05$.

\section{Results:}

Descriptive indicators of the demographic characteristic of women with hypertensive husbands are presented in Table I. The mean age of women with non- hypertensive husbands and women with hypertensive husbands were $34.16 \pm 4.6$ and $35.36 \pm 4.5$ respectively.

\section{Results are summerized in Table to to 4:}

Table I. Mean scores and standard deviation of personal characteristics of participants

\begin{tabular}{llll}
\hline Variable & Mean & SD & p Value \\
Age & 36.80 & 4.5 & $0.06^{*}$ \\
control & 35.08 & 4.6 & $0.06^{*}$ \\
Education & 2.08 & 0.84 & $0.75^{*}$ \\
control & 2.00 & 0.88 & $0.75^{*}$ \\
job & 1.1 & 0.43 & $0.83^{*}$ \\
control & 1.15 & 0.44 & $0.83^{*}$ \\
\hline
\end{tabular}

*-Not significant

As it has been revealed from the data that the mean for couple burnout (128.02 \pm 17.15$)$, sexual dysfunctional beliefs $(153.34 \pm 16.97)$ and sexual assertiveness (90.85 \pm 22.39$)$ in women with hypertensive husband was higher than women with non-diabetic husbands (Table II). In other words, mean difference results showed that differences exist between couples burnout, sexual dysfunctional beliefs and sexual assertiveness in one of the components of this variable in two groups. The results are presented in (Table II ).
Table-2:The mean and SD of research variables of all participants

\begin{tabular}{|c|c|c|c|c|c|c|}
\hline Tests & Variable & $\begin{array}{l}\text { Wome } \\
\text { hypert } \\
\text { husban }\end{array}$ & $\begin{array}{l}\text { with } \\
\text { nsive } \\
\text { d }\end{array}$ & $\begin{array}{l}\text { Womer } \\
\text { healthy } \\
\text { husban }\end{array}$ & with & $\mathrm{p}^{*}$ \\
\hline & & Mean & SD & Mean & SD & \\
\hline CBM & Couple burnout & 128.02 & 17.15 & 64.57 & 9.45 & $0.01^{*}$ \\
\hline & Physical burnout & 41.45 & 6.67 & 20.77 & 5.16 & $0.01^{*}$ \\
\hline & Emotional burnout & 44.28 & 6.07 & 21.73 & $5 \cdot 5^{2}$ & $0.01^{*}$ \\
\hline & Psychol. burnout & 42.28 & $5 \cdot 4$ & 22.25 & 4.66 & $0.01^{*}$ \\
\hline HISA & Sexual assertiveness & 90.85 & 22.39 & 67.81 & $13 \cdot 34$ & $0.01^{*}$ \\
\hline SDBQ & Age related beliefs & 153.34 & 16.97 & 120.57 & 19.15 & $0.01^{*}$ \\
\hline & Sexual self thought & 36.16 & 5.18 & 29.86 & 6.53 & $0.01^{*}$ \\
\hline & Denying Emo priority & 24.24 & $3 \cdot 55$ & 16.97 & 5.09 & $0.01^{*}$ \\
\hline & Motherhd. priority & 19.48 & 3.67 & 14.92 & $3 \cdot 78$ & $0.01^{*}$ \\
\hline & Sexual dysf. beliefs & 15.07 & 2.19 & 11.99 & $3 \cdot 5^{2}$ & $0.01^{*}$ \\
\hline & & $25 \cdot 93$ & 2.64 & 18.65 & 6.09 & \\
\hline & & 11.87 & 1.55 & 11.67 & $3 \cdot 34$ & \\
\hline
\end{tabular}

*p value significant $(\mathrm{p}<0.05)$ from student t- test Test.

After comparing couple burnout, sexual dysfunctional beliefs and sexual assertiveness in women with hypertensive and non-hypertensive husbands, ANOVA test was used to reveal the difference between the two groups (Table-3).

Table III: Analysis of variances (ANOVA Test) from CBM, HISA and SDBQ questionnaires

\begin{tabular}{|c|c|c|c|c|}
\hline State & Dependent variables & $\begin{array}{l}\text { Sum of } \\
\text { Squares }\end{array}$ & DF & $\begin{array}{l}\text { Mean of } \\
\text { Squares }\end{array}$ \\
\hline \multirow{3}{*}{ 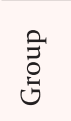 } & Sexual assertivness & 29980.57 & 1 & 29980.57188 .274 \\
\hline & Couple burnout & 227473.009 & 1 & 22473.0091186 .529 * \\
\hline & Sex. dysfunction belief & 60673.491 & 1 & $60673.491 \quad 185.321$ * \\
\hline \multirow{3}{*}{$\underset{t}{\circ}$} & Sexual assertiveness & $76077 \cdot 540$ & 224 & 339.632 \\
\hline & Couple burnout & 42943.717 & 224 & 191.713 \\
\hline & Sex.dysfunction belief & 73336.973 & 224 & 327.397 \\
\hline \multirow{3}{*}{ సٓ } & Sexual assertiveness & 1528399.000 & 226 & \multirow{3}{*}{$\begin{array}{l}{ }^{*} \mathrm{p}<0.0001 \\
\text { ANCOVA test }\end{array}$} \\
\hline & Couple burnout & 2365924.000 & 226 & \\
\hline & Sex. dysfunction belief & 4372791.000 & 226 & \\
\hline
\end{tabular}

After comparing couple burnout, sexual dysfunctional beliefs and sexual assertiveness in women with hypertensive and non-hypertensive husbands, LSD test was used to reveal the difference between the two groups since F-test results only showed an overall difference and do not determine whether the difference is beneficial for one of the groups. Results of the LSD test confirmed the difference between sexual problems, couple burnout, and sexual dysfunction scores between two groups had higher levels of couple burnout and sexual dysfunction beliefs and sexual assertiveness (Table-4).

Table-4: LSD test of mean scores of CBM, HISA \& SDBQ questionnaires

\begin{tabular}{llll}
\hline Variable & Mean (I-J) & SD & Significance \\
\hline Sexualassertiveness & 23.03 & 2.45 &. .ooo* \\
Couple burnout & 63.45 & 1.84 &. .ooo* $^{*}$ \\
Sexual dysfunctional beliefs & 32.77 & 2.40 & .ooo* \\
\hline
\end{tabular}

*Significance from LSD test 


\section{Discussion:}

We found a signif icant difference in the social parameters such as couple burnout, sexual dysfunction beliefs and sexual assertiveness between the couples i.e., women with hypertensive and non- hypertensive husbands. Sexual satisfaction improves the functions of the families, enhances couples' health, the longevity of relation and life satisfaction, in addition, it also considered as one of the basic needs in human life (Stackert \& Bursik, 2003). Sexual dysfunction is described as a stress factor that could reduce the quality of life and cause marital challenges (Lewis et al., 2004). Nevertheless, hypertension as one of the chronic disease is one of the essential cause of sexual dysfunction, but other parameters may influence sexual activity as well such as general condition, psychological disorders, and severe diseases affecting general condition, medication and partnership. Erectile dysfunction is one of the major barriers to the antihypertensive treatment. It has been shown that various antihypertensive drugs have a negative influence on sexual function (Khodabakhshi et al., 2014). According to a psychological study, women's sexual function has a positive correlation with their male partners' sexual function ( Cayan et al., 2004).

Khodabakhshi et al., (2004) revealed that women whose husbands are suffering from chronic diseases such as diabetes are also having lower sexual assertiveness, higher couple burnout and sexual dysfunctional beliefs as compared to the other women with the healthy spouse. Also, Afra, et al. (2016) assessed the relationship between ischemic heart disease and sexual Satisfaction and showed that men and the patients who do not receive cardiac medications have higher levels of sexual satisfaction. These results are in agreement with our finding that chronic disease and medication could affect sexual health. Since motherhood is greatly appreciated in our culture, women have higher scores of couple burnout (Bagshawe \& Taylor, 2003) Also, while the sexual relationship is weak or is not satisfying, couple burnout would be enhanced.

These results confirm our finding concerning the associations of couple burn out in couple suffering from chronic disease.

Also, women prefer the stability of their relationship to their own in a stable relationship to sexual desires and they do not express it correctly. This shows the state of their sexual assertiveness and also women in our culture sacrifice their psychological sexual desires for the stability of the relationship and sexual assertiveness would be lower in women with the sexual disorder (Khodabakhshi et al., 2014). These results are in contrast with our findings. In our study, sexual assertiveness in the women with hypertensive husbands was higher. It could be due to increasing sexual need of women with husbands suffering from sexual dysfunction due to hypertension. Based our cultural issue, women do not express their sexual needs. So, sexual health of families would be threatened.

Past researches indicate that patients with chronic disease may have sexual disorder due to low self-esteem, not having a proper imagination about body image and misconceptions about their ability in sexuality or challenges associated with their disease(Mahrer-Imhof et al., 2007; Balon, 2011). Also, Chiesa et al. (2003) showed that Valsartan (anti- hypertensive medication) reduces both Systolic blood pressure and diastolic Blood Pressure but improves sexual dysfunction significantly in patients with arterial hypertension. According to the finding of this study change of hypertensive medication in case of sexual dysfunction could be effective. The results of the above-mentioned studies are in agreement with the present study. Some limitations existed in our study. stressfulness and psychosocial problems in filing questionnaires and some of the women were not cooperative.

\section{Conclusion:}

Taken together, women whose husbands suffer from chronic diseases such as hypertension (which results in sexual dysfunction in patients) have higher sexual assertiveness and couple burnout and sexual dysfunctional beliefs compared with the other women. Therefore, psychotherapy of couples is highly recommended besides treatment of hypertension. If sexual dysfunction occurs due to antihypertensive medication, change of medication might be effective.

\section{Acknowledgements:}

The authors acknowledge Jahrom University of medical sciences and medical clinic affiliated to this university.

\section{References:}

Afra, L.A., Taghadosi, M. \& Gilasi, H.R. (2016): Relationship Between Ischemic Heart Disease and Sexual Satisfaction, Global J. Health Sci., 8(1):263-269

Bakhshayesh, A., \& Mortazavi, M.(2010): The relationship between sexual satisfaction, general health and marital satisfaction in couples. J. App. Psychol., 3(4):73-85.

Bagshawe, A., \& Taylor, A. (2003): ABC of subfertility: Counselling. BMI,327(7422):1038-1040.

Bai, F. (2009): The effect of treatment on the feminist desire and sexual rights among married women. Tehran, Tarbiat Moallem University. (In Persian).

Balon, R. (2011): Sexual Dysfunction: Beyond the Brain-Body Connection. Pub. By: Karger, Medical and Scientific publishers.

Bernhard, L.A. (2002): Sexuality and sexual health care for women. Clin. Obstet. Gynecol., 45(4):1089-1098.

Cayan, S., Bozlu, M., Canpolat, B., Akbay, E. (2004): The assessment of sexual functions in women with male partners complaining of erectile dysfunction: does treatment of male sexual dysfunction improve female partner's sexual functions?..Sex Marital Ther., 30(5):333-341. 
Esmaili, A., Amirsardari, L., \& Ansary, B. (2014): Comparison of Sexual Dysfunctions Among Employed Women and Housewives Attending's toTabriz Counseling Crescent Center, Iran. Iran. J.Heal. Sci., 2(4):46-51

Chiesa, A.D., Pfiffner, D., Meier, B. \& Hess, O.M. (2003), Sexual activity in hypertensive men. L.Hum.Hyperten., 17(8):515-521

Koolaee, K.A., Asadi, E., Mansoor, L., Mosalanejad, L. \& Fathabadi, A. (2014): A holistic approach to psychological sexual problems in women with diabetic husbands. Iran. J. Reprod. Med., 12(3).175-182

Lewis, R.W., Fugl-Meyer, K.S., Bosch, R., Fugl-Meyer, A.R., Laumann, E.O., Lizza, E., Martin-Morales, A. (2004): Epidemiology/risk factors of sexual dysfunction." J.Sex. Med. 1(1):35-39.
Mahrer-Imhof, R., Hoffmann, A., Froelicher, E.S. (2007): Impact of cardiac disease on couples' relationships. J.Adv. Nurs., 57: 513-521.

Navid, F. (2006): Evaluation and comparison of marital disenchantment with climate factors in the teacher hospital staff in Tehran. Tehran, Shahid Beheshti University. (In persian)

Nobre, P.J., Pinto-Gouveia, J. (2003): Sexual dysfunctional beliefs questionnaire: as vulnerability factors to sexual problems. $J$. Sex. Res., 43: 68-75.

Roberts, R.N. (2009): Sexual Dysfunction: the Brain-Body Connection. Obstet. Gynaecol. 11:226.

Sanaei, B. (2005): Measures of family and marriage. Beast Publisher;

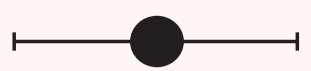

